\title{
Foreword to the Special Issue on Zero Emission Research and Technology Center testing field site, Bozeman, Montana, USA
}

\author{
Lee H. Spangler
}

Received: 17 November 2009/Accepted: 23 November 2009/Published online: 14 January 2010

(C) Springer-Verlag 2010

Carbon capture and storage in geologic formations is considered an important emerging technology for mitigating global climate change. Successful deployment of this technology will likely require monitoring techniques for storage verification, environmental monitoring, and public assurance. Near surface monitoring will play a vital role for public assurance, and a variety of technologies have already been implemented at other pilot sites.

Other sites, however, have been appropriately selected for storage and do not leak. So while they are extremely useful for understanding deep geologic behavior of $\mathrm{CO}_{2}$ (which was the primary goal), they yield little or no information about performance of near surface detection technologies, transport of $\mathrm{CO}_{2}$ in shallow zones, and shallow zone environmental effects.

The need for a site with controlled flux, the ability to start and stop flow to measure onset and recovery response times and with a large enough spatial extent to permit testing of most relevant detection technologies was recognized. The Zero Emission Research and Technology Center (ZERT, a collaborative involving three universities and six DOE national laboratories in the USA) has developed a site with controlled, shallow release of $\mathrm{CO}_{2}$.

This special issue of the journal presents the results of some of these controlled experiments at the ZERT site.

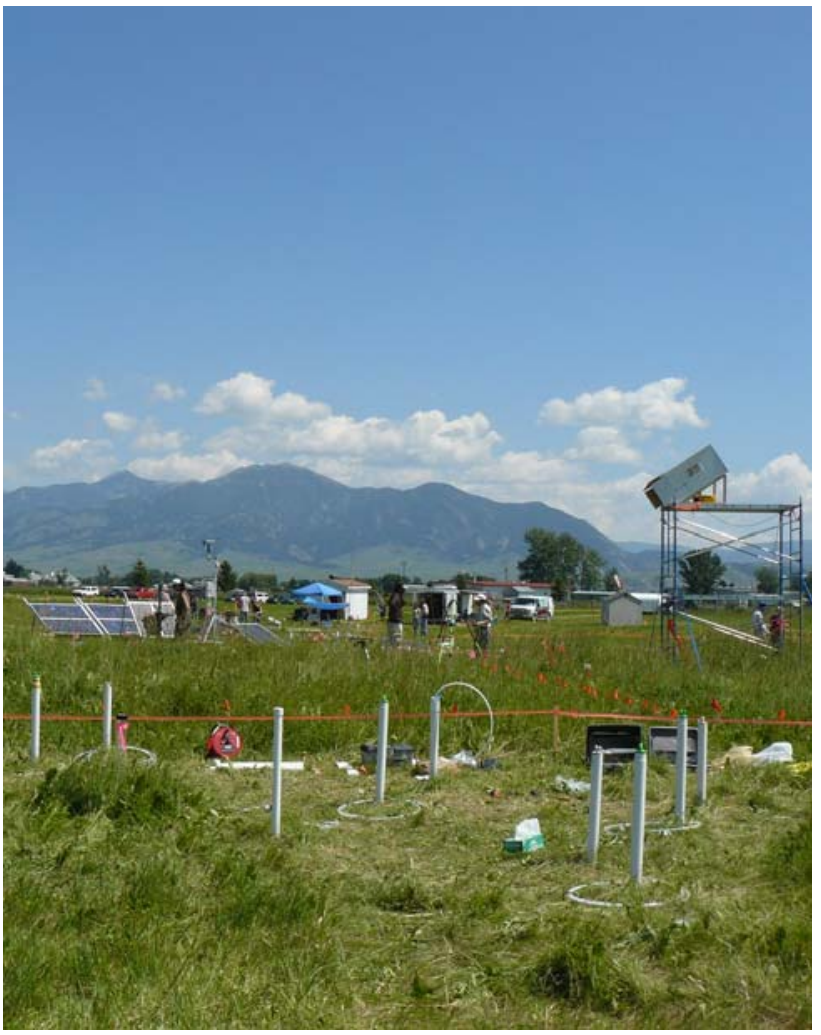

